\title{
DEVELOPMENT OF ASPHALT MIX STIFFNESS MODULUS MODEL USING SLAG MATERIALS AND RECLAIMED ASPHALT PAVEMENT
}

\author{
*Rindu Twidi Bethary ${ }^{1}$, Bambang Sugeng Subagio ${ }^{2}$, Harmein Rahman ${ }^{3}$ and Nyoman Suaryana ${ }^{4}$ \\ ${ }^{1,2,3}$ Faculty of Civil and Environment Engineering, Bandung Institute of Technology, Indonesia; ${ }^{4}$ Research \\ and Development Center of Road and Bridge, Ministry of Public Work and Public Housing, Indonesia
}

*Corresponding Author, Received: 17 Nov. 2019, Revised: 15 March 2020, Accepted: 04 April 2020

\begin{abstract}
One of the design parameters using mechanistic methods for structural evaluation of asphalt pavement is the modulus value obtained from the DSR test for asphalt modulus and UMATTA test for mixture modulus. Tests were carried out on hot mix asphalt with sixteen combinations using reclaimed asphalt pavement, EAF slag and a combination of both with a percentage of up to $30 \%$. The result of the mixture modulus showed that the mixture with a combination of slag and Reclaimed Asphalt Pavement (RAP) gave better performance compared to the control mixture using asphalt pen 60/70 and natural aggregate. The development of the mixture modulus model was analyzed statistically with the classical assumption test and the determination of dependent variables based on the existing theoretical model. The asphalt stiffness modulus was taken from the calibrated DSR test results, asphalt mix volumetric plus the variables of the RAP and slag percentage in this study. Of the several models obtained, there were two different mixture volumetric parameters the void in mix and void filled with asphalt in the mixture both models were validated to the stiffness modulus of the mixture. From the test results obtained, the closest ratio range was the stiffness modulus of mixture model with the void in mix parameter.
\end{abstract}

Keywords: Asphalt Stiffness Modulus, Stiffness Modulus of Mixture, Slag, Reclaimed Asphalt Pavement.

\section{INTRODUCTION}

One important parameter in pavement design is the stiffness describing the behavior of mechanical materials and allows the dimensions of the pavement system in layers. The modulus and thickness of each pavement layer allow structure analysis with stress and strain distribution under wheel loads [1], where the condition of most asphalt mixes is not elastic because it undergoes permanent deformation on each repetition of loads. However, if the load is relatively small compared to the strength of the material and undergoes a high repetition of loads so that the deformation that occurs at each repetition of loads is almost completely perfect and proportional to the loads, then the material is considered an elastic material [2].

Stiffness modulus is a fundamental mechanical parameter that expresses synthetically the structural properties of an asphalt mix determined through non-destructive tests and is very useful for conducting statistical evaluations of the effects of one or more components in the mechanical response of a mixture [3]. Stiffness Modulus of Mixture, in addition to being influenced by asphalt stiffness modulus also depends on the type of asphalt and aggregate used and the type of modification done. Both for its rheological properties and its mechanistic properties, where the modification is other than improving the overall mixture, is also environmentally friendly. An example is the utilization of waste, namely the use of RAP technology which is the result of the process of pavement scraping and utilizing artificial aggregates, one of which is the slag aggregate [4,5].

From the laboratory test results, used recycled slags and aggregates to analyze the dynamic characteristics of an asphalt mix using three types of aggregates, including dacite, steel slag, and recycled aggregate, through the Marshall method to determine optimum asphalt percentage. The results showed that the mixture with steel slag as coarse aggregate and recycled aggregate as fine aggregate showed a good performance [6]. Meanwhile, in conditions of the short-term and long-term aging test, there was a decrease in stability compared to the normal condition. This happened because of the reduced interlocking properties of slag aggregate with asphalt that has aged. This indicates that the asphalt oxidation occurred was not too high, thus causing the asphalt not to become harder and brittle [7].

Evaluated that the long-term aging of hot asphalt mix containing electric furnace steel slag was conducted by testing the Marshall stability and resilient modulus at temperatures of $25^{\circ} \mathrm{C}$ and $40^{\circ} \mathrm{C}$, indirect tensile strength and moisture susceptibility. 
In this experiment, the aggregate substitutes with steel slag can increase the value of stability, stiffness, resilient modulus, and indirect tensile strength and is recommended for use in hot asphalt mix [8]. The mixture stiffness modulus in the asphalt mix containing recycled aggregate and Electric Arc Furnace (EAF) slag also shows a higher value compared to the control mixture. The contribution of RAP materials to the increase in stability value is basically due to the effects of aging that occur on RAP asphalt. With the increasing use of RAP, the amount of asphalt aging integrated into asphalt concrete mix has also increased. The asphalt mix with EAF slag also shows a higher stiffness modulus, regardless of the RAP content in the mixture $[3,9,10]$.

\section{MATERIALS AND METHODS}

\subsection{Aggregate}

The aggregate material used in this asphalt mix consisted of three, which are the recycled aggregate (RAP), steel slag, and andesite aggregate. Recycled material was obtained from raking the Karawang national road, Indonesia. The steel slag used was the EAF slag type, which is the slag produced from the processing of steel that is cooked by the furnace using electrodes derived from steel waste. While the andesite aggregates were obtained from crushed stones from Karawang, Indonesia. The test results of the three aggregates as shown in Table 1.

Table 1 Aggregate Properties

\begin{tabular}{|c|c|c|c|}
\hline Test type & RAP & $\begin{array}{c}\text { Steel } \\
\text { slag }\end{array}$ & Andesite \\
\hline $\begin{array}{l}\text { Coarse } \\
\text { Aggregate } \\
\text { Specific Gravity }\end{array}$ & 2.496 & 3.488 & 2.642 \\
\hline $\begin{array}{l}\text { Fine Aggregate } \\
\text { Specific Gravity }\end{array}$ & 2.442 & 3.086 & 2.614 \\
\hline $\begin{array}{l}\text { Abrasion with } \\
\text { LA Machine }\end{array}$ & 32.30 & 13.01 & 21.17 \\
\hline
\end{tabular}

The specific gravity for steel slags was higher than the specific gravity for conventional aggregates, especially for coarse aggregates. This was caused by the metal content in the slag aggregate. The difference in density that was large enough will result in differences in volume with the same weight and the amount of absorption of different water will affect the amount of optimum asphalt needed from the Marshall test. Based on the RAP aggregate test results, the hardness was $32.30 \%$ and the specific gravity was about 2.5 . Some advantages of using slag are highly angular in shape and have rough surface texture [11].

The gradation used in this study was the Asphalt
Concrete - Binder Course (AC-BC) [12], the design RAP gradations obtained from the gradation filter analysis experiment were within the upper and lower limits of the reference gradation used in the study, as result of combined gradation between the new aggregate and the RAP aggregate, was set adjusted to be line in the middle line of Asphalt Concrete - Binder Course (AC_BC) gradation [4], while the gradation slag aggregate gradation was similar to the reference gradation because slag aggregate for all filter sizes was available, as shown in Fig 1.

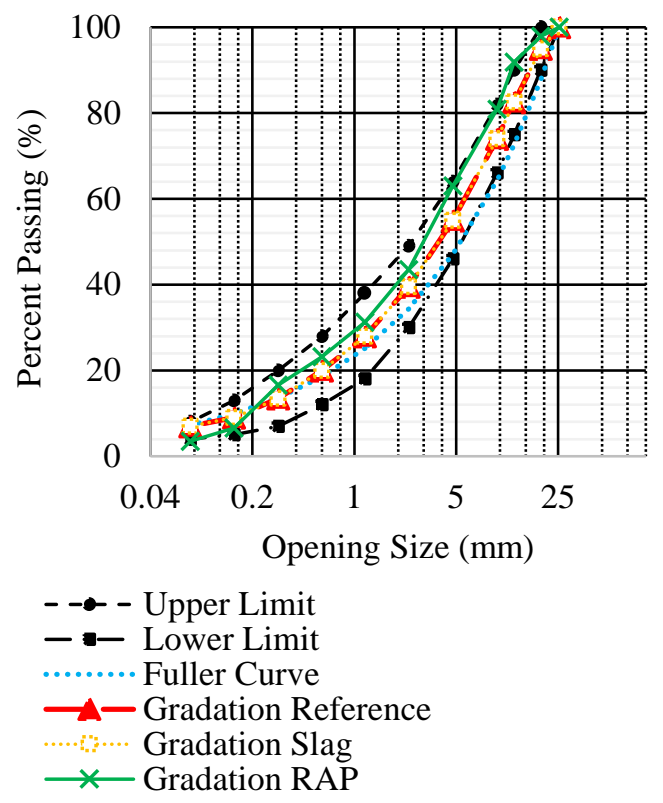

Fig.1 Aggregate Gradation

\subsection{Asphalt}

There were two asphalt materials used, they are the asphalt produced from RAP material and original asphalt with 60/70 penetration, Table 2 presents the modified asphalt properties.

Table 2 Asphalt Properties

\begin{tabular}{lccc}
\hline \multicolumn{1}{c}{ Test type } & RAP & $\begin{array}{c}\text { RAP+ } \\
\text { Reclamite }\end{array}$ & $\begin{array}{c}\text { Pen } \\
60 / 70\end{array}$ \\
\hline $\begin{array}{l}\text { Asphalt } \\
\text { Content }\end{array}$ & $5.1 \%$ & - & - \\
$\begin{array}{l}\text { Penetration } \\
25^{0} \mathrm{C}\end{array}$ & 10 & 62.04 & 64.7 \\
$\begin{array}{l}\text { Softening Point } \\
{ }^{0} \mathrm{C}\end{array}$ & 80 & 52.95 & 51 \\
Ductility & 38 & 100 & 100 \\
\hline
\end{tabular}

Tests of the characteristics of RAP asphalt included the percentage of RAP asphalt content using Trichloroethylene (TCE) liquid, while the separation of asphalt from TCE liquid used an 
evaporator to determine the RAP asphalt content where the asphalt content would affect the new asphalt pen $60 / 70$ which would be added to the hot asphalt mix. To rejuvenate the RAP asphalt, its characteristics are close to controlling asphalt penetration 60/70, Reclamite ${ }^{\circledR}$ rejuvenating material was used by using an approach to the softening point value and its penetration. An optimum Reclamite ${ }^{\circledR}$ content of $23 \%$ was obtained to be mixed into the RAP asphalt which was expected to restore its characteristics so that it approaches the control asphalt pen 60/70 [4].

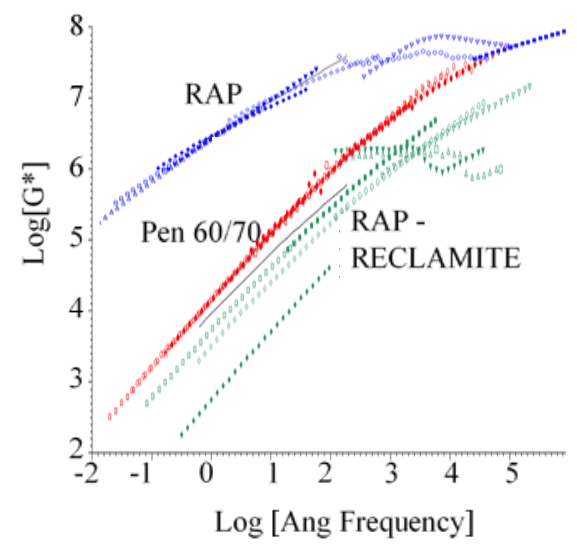

Fig.2 Master Curve

Based on Fig 2 master curve illustrated that the level of asphalt sensitivity to changes in temperature and frequency of loads, the asphalt pen $60 / 70$ has a fent slope. This indicates that the temperature range and loading time were getting wider so that it is easy to be applied in the field, as well as for Reclamite-added RAP asphalt to approaches the master curve of asphalt pen 60/70 which means that Reclamite rejuvenating material can increase the temperature range and loading time when compared to RAP asphalt without rejuvenating material, which is steeper because the RAP asphalt was [13].

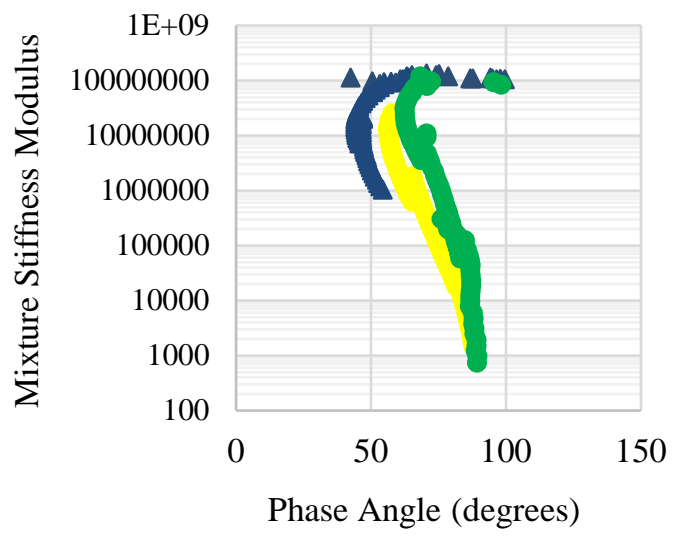

Fig.3 Black Diagram
The relationship of asphalt stiffness modulus and phase angle $(\delta)$ is depicted in a black diagram as seen in Fig. 3 in the RTFOT conditions with $\delta$ values ranging between $40-100$. The addition of Reclamite rejuvenating material to RAP asphalt affects the asphalt stiffness modulus value, where the asphalt stiffness modulus value will decrease, as well as an increase in $\delta$ on Reclamite-added RAP asphalt. This showed that the asphalt is more viscous to the asphalt pen 60/70 compared to RAP asphalt without rejuvenating material.

\subsection{Methods}

This study used 16 mixture designations in which there were variations in the percentage of slag and RAP with one mixture as a control using natural aggregate and asphalt pen 60/70 as shown in Table 3. Using the Marshall method, it is known that the optimum asphalt content in each mixture combination will be used for the mixture resilient modulus test, where further discussion regarding the determination of optimum asphalt content can be seen in another paper that has been presented by the author $[5,13]$.

Table 3 Mixture Designation

\begin{tabular}{cccc}
\hline Aggregate & RAP & $\begin{array}{c}\text { Steel } \\
\text { slag }\end{array}$ & Andesite \\
\hline C0 & - & - & 100 \\
CS1, CS2, & - & $\begin{array}{c}10,20, \\
\text { CS3 }\end{array}$ & $30,80,70$ \\
CR1, CR2, & 10,20, & - & $90,80,70$ \\
CR3 & 30 & & \\
CS1R1 & 10 & 10 & 80 \\
CS1R2 & 20 & 10 & 70 \\
CS1R3 & 30 & 10 & 60 \\
CS2R1 & 10 & 20 & 70 \\
CS2R2 & 20 & 20 & 60 \\
CS2R3 & 30 & 20 & 50 \\
CS3R1 & 10 & 30 & 60 \\
CS3R2 & 20 & 30 & 50 \\
CS3R3 & 30 & 30 & 40 \\
\hline
\end{tabular}

The asphalt stiffness modulus can be determined based on a laboratory test using Dynamic Shear Rheometer (DSR) [14], with a test frequency of 10 $\mathrm{rad} / \mathrm{s}$ and the test temperature that refers to the temperature range contained in the PG [15]. The test was carried out on three asphalt conditions: original, RTFOT and PAVT. The parameters obtained were complex shear modulus and phase angle. This value can estimate the stiffness modulus [16], as in

Sbit $=2(1+\mu) G^{*}$ 
Where,

$\mu=$ Poisson number

$\mathrm{G}^{*}=$ complex shear modulus

The resilient modulus test in the laboratory was carried out by indirect tensile strength test, using the UMATTA tool as shown in Fig. 4 [17], with a loading pulse width of $250 \mathrm{~ms}$, pulse repetition period of $3000 \mathrm{~ms}$, and carried out on temperature variations concerning for to fluctuations in temperature at the pavement, which were at temperatures of $20^{\circ} \mathrm{C}, 25^{\circ} \mathrm{C}, 35^{\circ} \mathrm{C}$ and $45^{\circ} \mathrm{C}$.

The determination of mixture stiffness modulus can also be done using several mathematical models, the model used as a comparison in this study was the Nottingham model [18] using Eq. (2).

$\operatorname{Smix}=\operatorname{Sbit}\left(1+\frac{2,5 \mathrm{Cv}}{\mathrm{n}(1-\mathrm{Cv})}\right)^{\mathrm{n}}$

Where,

Smix =stiffness modulus of mixture (Mpa)

Sbit =asphalt stiffness modulus ( $\mathrm{MPa})$

$\mathrm{Cv}$ =aggregate concentration (\%).
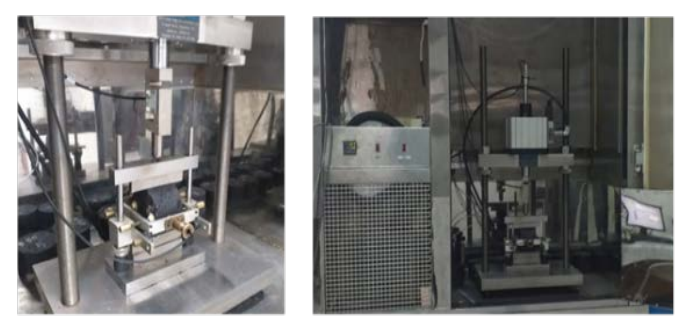

Fig.4 UMATTA Test Equipment

\section{RESULT AND DISCUSSION}

\subsection{Asphalt Stiffness Modulus}

The value of asphalt modulus based on the results of the laboratory test using DSR was seen from the complex modulus approach $\left(\mathrm{G}^{*}\right)$ refer to Eq.(1) for frequency sweep test condition at the loading time of 0.25 based on the mixture stiffness modulus in the experiment with the UMATTA tool, while the asphalt stiffness modulus theoretically used the Van der Poel nomogram in Fig.5.

Based on Fig. 5, the asphalt stiffness modulus from the DSR test results for asphalt pen 60/70 was higher than that of Reclamite-added RAP asphalt. Basically, this is due to the characteristics of the rejuvenating material that make RAP asphalt that has aged return into asphalt that is new and more liquid. From the comparison of experimental and nomogram results, the asphalt stiffness modulus value of the DSR test results was smaller compared to the Van der Poel nomogram.

This difference was due to the different approach assumptions which for this nomogram were used for conventional asphalt. While experimentally, it was possible to use modified asphalt. Therefore, a calibration factor was needed using statistical calculations. A calibration factor of 0.83 was obtained, which was multiplied by the asphalt stiffness modulus of the nomogram to get the stiffness modulus of the modified experiment asphalt. This value would be used in developing the stiffness modulus of mixture model.

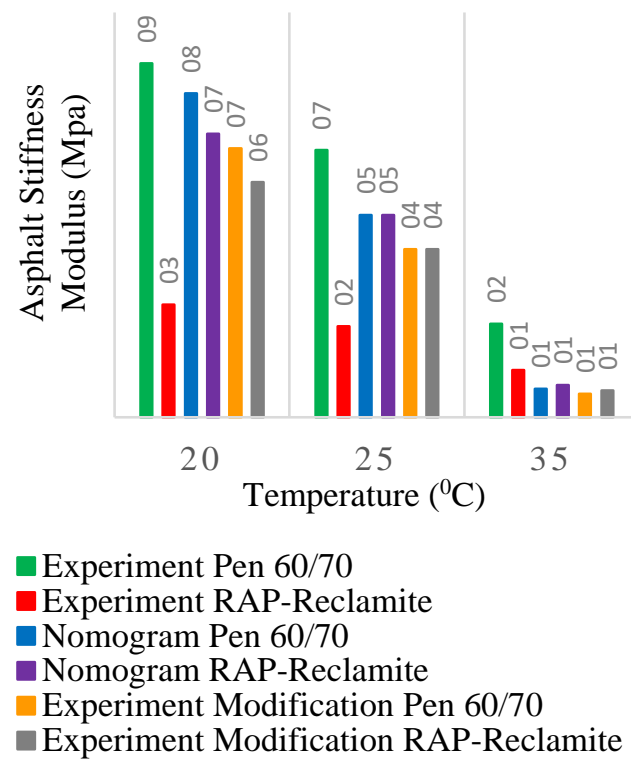

Fig.5 Asphalt Stiffness Modulus

\subsection{Stiffness Modulus of Mixture}

The temperature on the mixture stiffness modulus value of the HMA mixture using either RAP, slag or a combination of both with increasing temperature made the stiffness modulus of mixture value lower. This was due to changes in the viscoelastic (changing from elastic into viscous) mechanical property of asphalt that caused a decrease in the stiffness modulus in asphalt mix at $25^{\circ} \mathrm{C}$ as shown in Fig. 6.

It can be seen that the stiffness modulus of the theoretical mixture using the Nottingham model refer to Eq. (2) that the results were smaller than using this experiment because of the difference in the approach used. The test with the UMATTA tool was conducted based on the maximum load given and the resulting strain, while the Nottingham model was done by predicting the stiffness modulus based on the value of asphalt stiffness modulus, asphalt volume, and aggregate volume.

Increasing the slag percentage in the mixture increases the modulus value (Fig. 6) caused the volumetric characteristics of the mixture. Increasing slag percentage (CS10-CS30) in the asphalt mix resulted in an increased value of void in mix (VIM) and decrease in the value of void in mineral aggregate (VMA) and surface roughness 
characteristic in the slag aggregate, giving a greater stiffness modulus of mixture modulus than the control mixture.

An increase in the percentage of RAP (CR10CR30) in the asphalt mix could increase the stiffness modulus of the mixture. This could be caused by the asphalt contained in RAP material that had undergone aging was integrated into with hot mix asphalt. This was also seen when RAP and slag material were combined. The test results show that the stiffness modulus of the mixture value of the CR30S10-S30 mixture was higher than the control mixture, as well as when compared to the mixture of CR10S10-S30 and CR20S10-30. This showed that with an increase in RAP and slag in the hot mix asphalt, the stiffness modulus of mixture value also increased. This was due to the volumetric characteristics of the mixture which had a higher air void in mix value in the CR30S30 mixture.

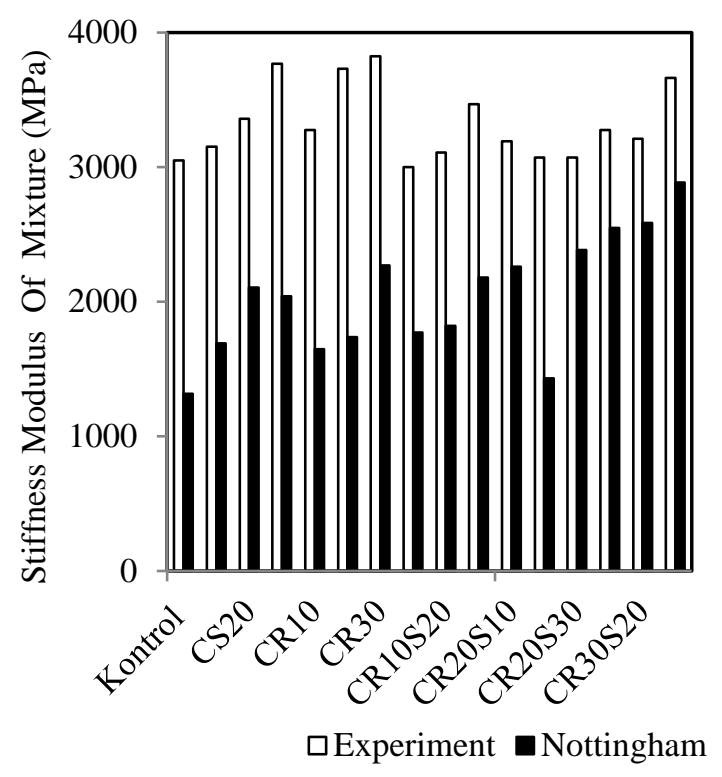

Fig.6 Stiffness Modulus of Mixture

\subsection{Stiffness Modulus of Mixture Model}

The asphalt mixture modulus model approach was developed based on the behavior of elastic material obtained from laboratory test results. The prediction model used regression analysis with dependent variables (stiffness modulus of mixture) and some independent variables [19]. The analysis was performed with SPSS software, with the classic assumption test as follows [20-22]:

1. Determination of multicollinearity occurs when there are more than two correlating variables, seen from the value of tolerance and variance inflation factor (VIF) where the tolerance value $>0.10$ and $\mathrm{VIF} \leq 10$.

2. Autocorrelation is to see if there is a linear relationship among errors in a series of observations, sorted by time with the Durbin Watson test refer to Eq. (3). If the calculated DW value limit is outside the lower limit $(\mathrm{dL})$ and the upper limit $(\mathrm{dv})$, then the model is no autocorrelation.

$D-W=\frac{\sum\left(e_{t}-e_{t-1}\right)}{\sum e_{t}^{2}}$

Where,

$\mathrm{D}-\mathrm{W}=$ Durbin Watson value

Et $\quad=$ Error at $\mathrm{i}-$ th $(\mathrm{i}=1,2, \ldots . \mathrm{n})$

3. The Objective determination of data should have a normal distribution, which means the data has spread evenly so it can represent the population, and can be distinguished that the skewness level.

4. To determine whether the regression model is Homoskedasticity, the variance from one observation to another observation can be seen from the graph between the predictive value of the dependent variable and the residual.

5. To determine whether two or more variables have a significant linear relationship or not. If the relation between variables is not linear, the other correlations should be tested, for example ie; quadratic or logarithmic correlations.

Based on analysis statistical with the classic assumption test obtained two models that meet the requirements were selected, Eq (4) and (5).

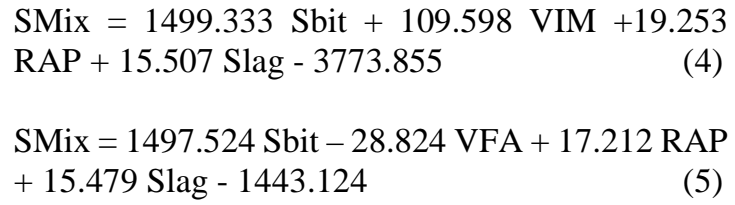

SMix $=1497.524$ Sbit -28.824 VFA + 17.212 RAP

+15.479 Slag - 1443.124

Where,

Smix =Stiffness Modulus of Mixture $(\mathrm{Mpa})$

Sbit $=$ Stiffness Modulus of Asphalt (Mpa)

VIM = Void in Mix (\%)

VFA $=$ Void Filled with Asphalt (\%)

RAP $=$ Reclaimed Asphalt Pavement (\%)

From the two models, we can assess the overall model fit using the (adjusted) R2 and the significance of the F-value the result of a one-way analysis of variance (ANOVA). When we interpret the model fit, the F-test is the most critical, as it determines if the overall model is significant. Table 4 shows the R2 value it is known that the model D is greater than the model $\mathrm{B}$, this indicates the model $\mathrm{D}$ can provide almost all the information needed to predict variations in the dependent variable (Smix).

The analysis was performed using 95\% confidence level $(\alpha=0.05)$, in Table 4 with ANOVA 
test from model B and model D where the F-statistic was greater than F-value which represent relationship between the independent variable (stiffness modulus of asphalt, void in mix, void filled with asphalt, RAP and slag) and the dependent variable (stiffness modulus of mixture). This finding is consistent with that the $\mathrm{p}$-value of the F-test is below 0.05 (i.e., a significant model). However, it automatically meant that all of our regression coefficients were significant effect the stiffness modulus of mixture.

Refer to Eq (4) and (5) that all variables statistically affected the stiffness modulus of mixture, this finding was consistent with the existing model, while increase asphalt stiffness modulus and percentage RAP at increased stiffness modulus of mixture. This phenomenon can be attributed to the higher aging rate at higher percentage asphalt in the mixture as well as increment percentage slag contributed to higher stiffness modulus of mixture.

\subsection{Model Validation}

To validate the proposed model, the database of the test results of the stiffness modulus of mixture in the laboratory were compared to the modulus predicted by the model. It can be seen in fig. 5 that it had linear line densities that are close together. The average ratio has a value close to 1.0 for the Eq (4), while for the Eq (5) the average ratio is 1.08.

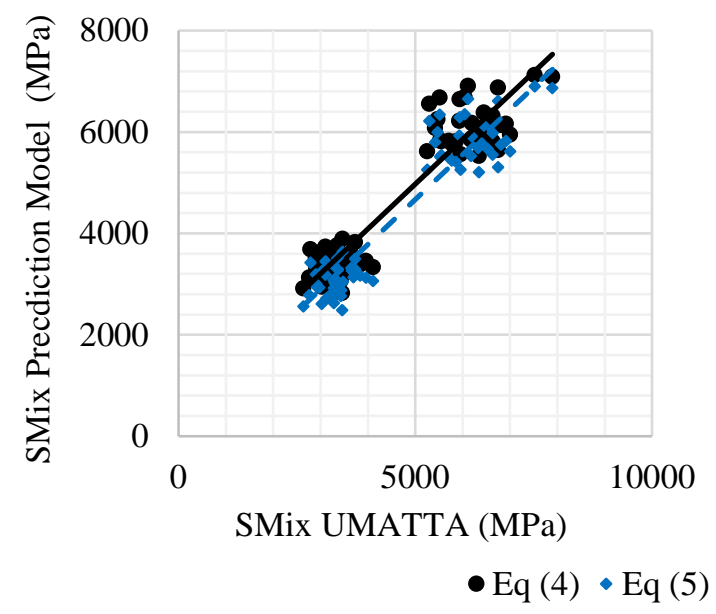

Fig.7 Suitability the Stiffness Modulus Mixture

From the result of the R2 value, it is known that the model $\mathrm{D}$ was greater than the model $\mathrm{B}$, but in the selection of the regression model, the coefficient of determination (R2) was one of and not the only criterion for choosing a good model, because if a linear regression estimate produces a high coefficient of determination but it was not consistent with the theory chosen by the researcher, then the model was not the best estimator model. In the development of the asphalt mix prediction model, the model B was chosen because it has a higher average ratio value and illustrates that the modulus result of this prediction model is closest to the result of the direct test modulus with UMATTA. Also, this model has consistent values for all the basic data models.

\section{CONCLUSION}

Based on the analysis and discussion of the development of stiffness modulus of mixture prediction model, the following conclusions were obtained:

1. The asphalt stiffness modulus produced by a laboratory test with DSR was lower than theoretically using Van Der Poel Nomogram. Then, a statistical analysis was done to obtain the modification DSR asphalt stiffness modulus that would be used in the development of asphalt mix stiffness modulus prediction model.

2. An increase in the stiffness modulus of mixture was seen in asphalt mix through an increase in the percentage of slag and RAP. This related to surface roughness in slag aggregate. This also applies to mixtures containing RAP. This was caused by the asphalt found in RAP material that had undergone aging, then integrated into with hot mix asphalt. The mixture with the largest modulus was found in the CR30S30 mixture.

3. Parameters for determining variables in the development of stiffness modulus of mixture model used theoretically. Based on the Nottingham model stiffness modulus model for hot mix asphalt containing slag and RAP was chosen with the following equation: SMix = 1499.333 Sbit + 109.598 VIM + 19.253 RAP + 15.507 Slag -3773.855.

\section{ACKNOWLEDGMENT}

The Author acknowledgment support from Indonesia Endowment Fund for Education (LPDP), Ministry of Finance, Republic of Indonesia.

\section{REFERENCES}

[1] Mellizo, C., Dore, G., Bilodeau J.P., Resilient Modulus Estimation for Granular Materials.11th International Conference on Asphalt Pavements, Nagoya, Japan, 2010, pp. 650-658.

[2] Huang, Y.H., Pavement Analysis and Design, Pearson Prentice Hall. New Jersey, USA, 2004.

[3] Baldo, N., Manthos, E., Pasetto, M., Nikolaides, A. F., Comparative analysis of stiffness modulus and fatigue resistance of asphalt 
concrete containing RAP materials, in: F.Canestrari, M.N. Partl (Eds), Proceedings 8th RILEM International Symposium on Testing and Characterization of Sustainable and Innovative Bituminous Materials, Rilem Book Series, Vol.11 Springer, Netherlands Dordrecht, 2016, pp. 915-926.

[4] Bethary, R.T., Subagio, B.S., Rahman, H., Suaryana, N., Effect of recycled materials on marshall performance of hot asphalt mixture (HMA-RAP), IOP Conf. Series, Materials Science and Engineering 508, 2019, pp. 1-6.

[5] Bethary, R.T., Subagio, B.S., Rahman, H., Suaryana, N., Effect of Slag and Recycled Materials on The Performance of Hot Mix Asphalt (AC-BC), Journal of Civil Engineering Vol.26, No 1, 2019, pp. 1-9.

[6] Arabani, M., Azarhoosh, A.R., The effect of recycled concrete aggregate and steel slag on the dynamic properties of asphalt mixtures. Construction and Building Materials 35, 2012, pp. 1-7.

[7] Bethary, R.T., Subagio, B.S., Rahman, H., Suaryana, N., Aging Effect Condition on Hot Asphalt Mixtures Marshall (AC-BC) Performance by Using Slag, IOP Conf. Series, Materials Science and Engineering 673, 2019, pp. 1-6.

[8] Masoudi, S., Abtahi, S.M., Goli, A., Evaluation of electric arc furnace steel slag coarse aggregate in warm mix asphalt subjected to long-term aging, Construction and Building Materials 135, 2017, pp. 260-266.

[9] Baldo, N., Pasetto, M., Dissipated energy analysis of four-point bending test on asphalt concretes made with steel slag and RAP. International Journal of Pavement Research and Technology 10, 2017, pp. 446-453.

[10] Pasetto, M., Baldo, N., Influence of the aggregate skeleton design method on the permanent deformation resistance of stone mastic asphalt, Mater. Res. Innov, 18 (S3), 2014, pp. S96-S101.

[11]Zaika Y, and Djakfar L., Gradation Band of Some Types Material for Reservoir Base of Porous Pavement. International Journal of GEOMATE, Vol. 11, Issue 25, 2016, pp. 24862492.

[12] Directorate General of Highways, Ministry of Public Works, General Specifications for Roads and Bridges, 2010, pp. 6.27-6.63.

[13]Bethary, R.T., Subagio, B.S., Rheological
Characteristics of Reclaimed Asphalt Pavement (RAP) Evaluation using Reclamite Rejuvenating Material. In: The 6th AMMSE Conference on Advanced Materials, Mechanics and Structural Engineering, Seoul, South Korea, 2019, pp. 1-6.

[14]AASHTO T315-10., Determining the Rheological Properties of Asphalt Binder Using a Dynamic Shear Rheometer (DSR), 2012, pp. 1-32.

[15] AASHTO M 320., Standard Specification for Performance-Graded Asphalt Binder, 2017, pp. 1-8.

[16] Read, J., Whiteoak, D., The Shell Bitumen Handbook, London, Thomas Telford, 2003.

[17]ASTM D4123., Standard Test Method for Indirect Tension Test for Resilient Modulus of Bituminous Mixtures. Annual Books of ASTM Standard, ASTM, 2003, West Conshohocken, pp. 1-4.

[18] Brown, S.F., Brunton, J.M., An Introduction to the Analytical Design of Bituminous Pavements, Second Edition. University of Nottingham, UK, 1984.

[19] Gujarati, D., Basic Econometric. Mc-Grawhill. New York, 2003.

[20] Ainiyah, N., Deliar, A., Vitriana, R., 2016. Assumption Test to Driving Factors of Land Cover Change In The Development Region Of Northern Part Of West Java: The Classica. The International Archives of the Photogrammetry, Remote Sensing and Spatial Information Sciences, Vol.XLI-B6, 2016 XXIII ISPRS Congress, 12-19 July 2016, pp. 205-210.

[21] Sarstedt, M., Mooi, E., A Concise Guide to Market Research (The Process, Data, and Methods Using IBM SPSS Statistics) second edition, Springer, New York, 2014, pp. 161200.

[22] Subagio, B.S., Maha, I., Affandi, F., Rahman, H., Performance and Development of Resilient Modulus and Fatigue Life Predictive Model of Warm Mix Asphalt Concrete Binder Course (AC-BC) Containing Reclaimed Asphalt Pavement (RAP), Eight International Conference on Maintenance and Rehabilitation of Pavements, Singapore, 2016, pp. 105.1-8.

Copyright (C) Int. J. of GEOMATE. All rights reserved, including the making of copies unless permission is obtained from the copyright proprietors. 